\title{
Thermal Expansion of Some Nickel Alloys
}

\author{
Peter Hidnert
}

\begin{abstract}
Data on the linear thermal expansion of some nickel alloys (manganese nickel, Hoskins Alloy 667, Inconel, Evanohm, Monel metal, M-M-M alloy, Illium alloy, and Waspalloy) for various temperature ranges between $20^{\circ}$ and $1,000^{\circ} \mathrm{C}$ are given. During the first heating of Inconel alloys (probably with a supersaturated content of carbon), irregularities were noted in the expansion at about $700^{\circ} \mathrm{C}$ and were ascribed to precipitation of carbide. The coefficients of expansion of the alloys are tabulated. For the range $20^{\circ}$ to $300^{\circ} \mathrm{C}$, these coefficients varied from 13.1 to $15.5 \times 10^{-6}$ per deg C. The effects of additions of copper, cobalt, and iron to nickel-chromium alloys (0 to 24 percent of chromium) are indicated.
\end{abstract}

\section{Introduction}

Data obtained between 1918 and 1956 on the linear thermal expansion of some nickel alloys for various ranges between $20^{\circ}$ and $1,000^{\circ} \mathrm{C}$, are presented.

\section{Alloys Investigated}

The samples of nickel alloys were obtained from Wilbur B. Driver Co., Newark, N. J., General Electric Co., Schenectady, N. Y., Holabird Quartermaster Intermediate Depot, Baltimore, Md., Hoskins Manufacturing Co., Detroit, Mich., Manning, Maxwell, and Moore, Inc., Bridgeport, Conn., National Advisory Committee for Aeronautics, Washington, D. C., National Bureau of Standards, The Standard Calorimeter Co. (succeeded by Burgess-Parr Co., Freeport, Ill.), and Universal Cyclops Steel Corp., Titusville, $\mathrm{Pa}$. The length of each sample used in the determinations of linear thermal expansion was $300 \mathrm{~mm}$. The cross sections of the samples, their chemical compositions, and treatments are given in table 1. The chemical compositions of some of the samples were determined by the Bureau as noted in footnotes of table 1 . The compositions of the other samples were supplied by the companies that produced them.

\section{Apparatus}

The micrometric thermal-expansion apparatus described by Hidnert and Souder [1] ${ }^{1}$ was used for the determinations of the linear thermal expansion of the nickel alloys. The samples were heated in an oil bath or an air furnace. To minimize the effects of oxidation or scaling at high temperatures, an observation wire was placed in a sharp $V$-groove cut around the sample near each end. Observations at each temperature were taken under equilibrium conditions.

\section{Results and Discussion}

The observations obtained on heating and cooling 15 samples to various temperatures were plotted,

1 Figures in brackets indicate the literature references at the end of this paper. but the observations for only 5 samples are shown (figs. 1, 3, 4). The coefficients of expansion in table 1 were all computed from the original expansion curves.

The "annealed" samples of Inconel, ${ }^{2}$ containing 0.02 to 0.11 percent of carbon, were probably in a supersaturated condition with respect to carbon on account of their relatively fast cooling from $2,050^{\circ} \mathrm{F}$ $\left(1,121^{\circ} \mathrm{C}\right)$. On the first heating of these alloys during the thermal-expansion determinations (fig. 1), slight irregularities were observed at about $500^{\circ}$ and $700^{\circ} \mathrm{C}$ in the curves of instantaneous coefficients of expansion versus temperature (fig. 2). The irregularities at about $500^{\circ} \mathrm{C}$ have been attributed [2a], although without conclusive evidence, to the formation of an ordered structure based upon the compound $\mathrm{Ni}_{3} \mathrm{Cr}$.

The author believes that the irregularities in Inconel at about $700^{\circ} \mathrm{C}$ (fig. 2) were caused by precipitation of carbide. Such irregularities have previously been reported by Hidnert [3] for nickelchromium-iron alloys. The irregularities in the latter alloys were observed only during the first heating on alloys that had previously been cast or quenched from a high temperature.

Figure 2 indicates that during the first heating of Inconel, the magnitude of the irregularity at $700^{\circ} \mathrm{C}$ increases with increase in the carbon content.

No irregularities were observed in the curves of Inconel on cooling it from $1,000^{\circ} \mathrm{C}$ to room temperature. The author believes that the expansion curves of each sample on repeated slow heating and slow cooling will closely follow the curve obtained on the first cooling from $1,000^{\circ} \mathrm{C}$ to room temperature. From this it follows that the coefficients of expansion on repeated heating and cooling for each sample should be the same or nearly the same as those given in table 1 on cooling.

Observations on thermal expansion of Monel metal (sample 1861) at various temperatures from room temperature to $1,000^{\circ} \mathrm{C}$ are shown in figure 3 . The expansion was not reversible on heating and cooling the sample during the first test, but the expansion was reversible during the second test.

2 W. J. O'Sullivan, Jr. [2] reported data on thermal expansion, specific heat, thermal conductivity, mechanical properties, electrical resistance, and emissivity of Inconel containing 0.02 to 0.11 percent of carbon. 
TABLE 1. Coefficients of linear thermal expansion of some nickel alloys

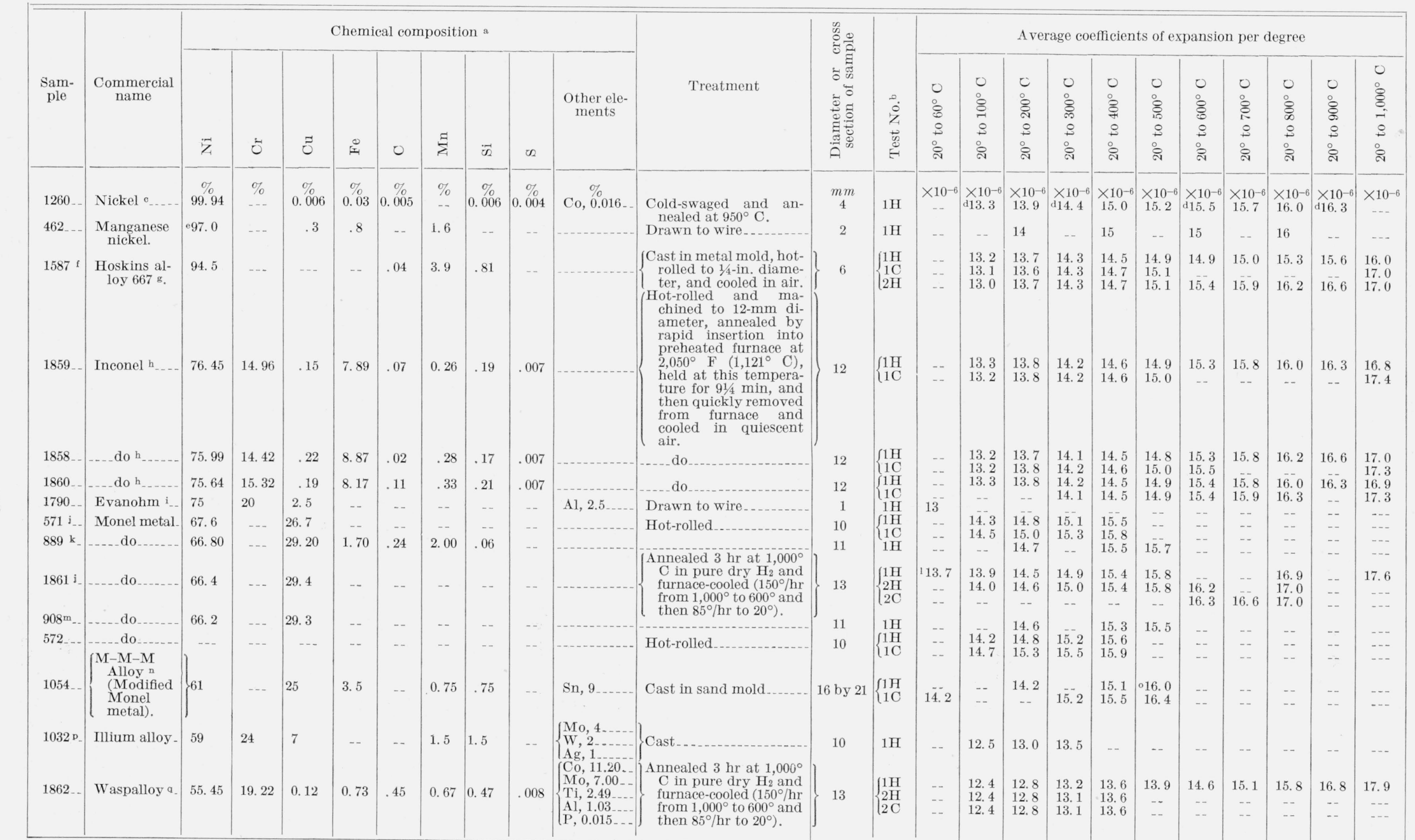

All compositions are given in percent by weight heating, and $\mathrm{C}$ indicates that they were obtained were obtained on samples.

c Added for comparison with the nickel alloys in this paper.

H. Swanger The properties of pure nickel, BS J. Jordan and W (1930) RP257. The coefficients of expansion for other temperature ranges were computed from the original observations.

Includes cobalt, probably as much as 1 percent.

( Bureau. $\mathrm{g}$ Used in the manufacture of spark plugs and may be classed as a h Made by International Nickel Co. Chemical composition determined by this company.

Made by Wilbur Driver Co., Newark, N. J.
j Chemical composition determined by E. E. Maczkowske of the Chemical composition determined by E. E. Maczkowske of the
Chemistry Division of the Bureau.
$\mathrm{k}$ Cut from valve stem.

H. A. Buchheit, formerly of the Bureau

One-third of the average coefficient of cubical thermal expansion $\left(41.0 \times 10^{-6}\right.$ per deg $\mathrm{C}$ from $4^{\circ}$ to $66^{\circ} \mathrm{C}$ ) determined on another sample Mechanics Division of the Bureau.
${ }^{m}$ Cut from valve stem. Chemical composition determined by E. E. Maczkowske of the Chemistry Division of the Bureau.
$n$ Resistant to acid and erosion by high-temperature, high-pressure steam. Hidnert and W. T. Sweeney, Thermal expansion of M-M-M

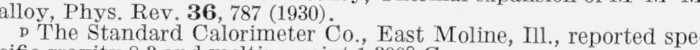
cific gravity 8.3 and melting point $1,300^{\circ} \mathrm{C}$.

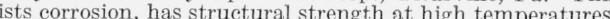
and is used for rotor blades in turbojets. 


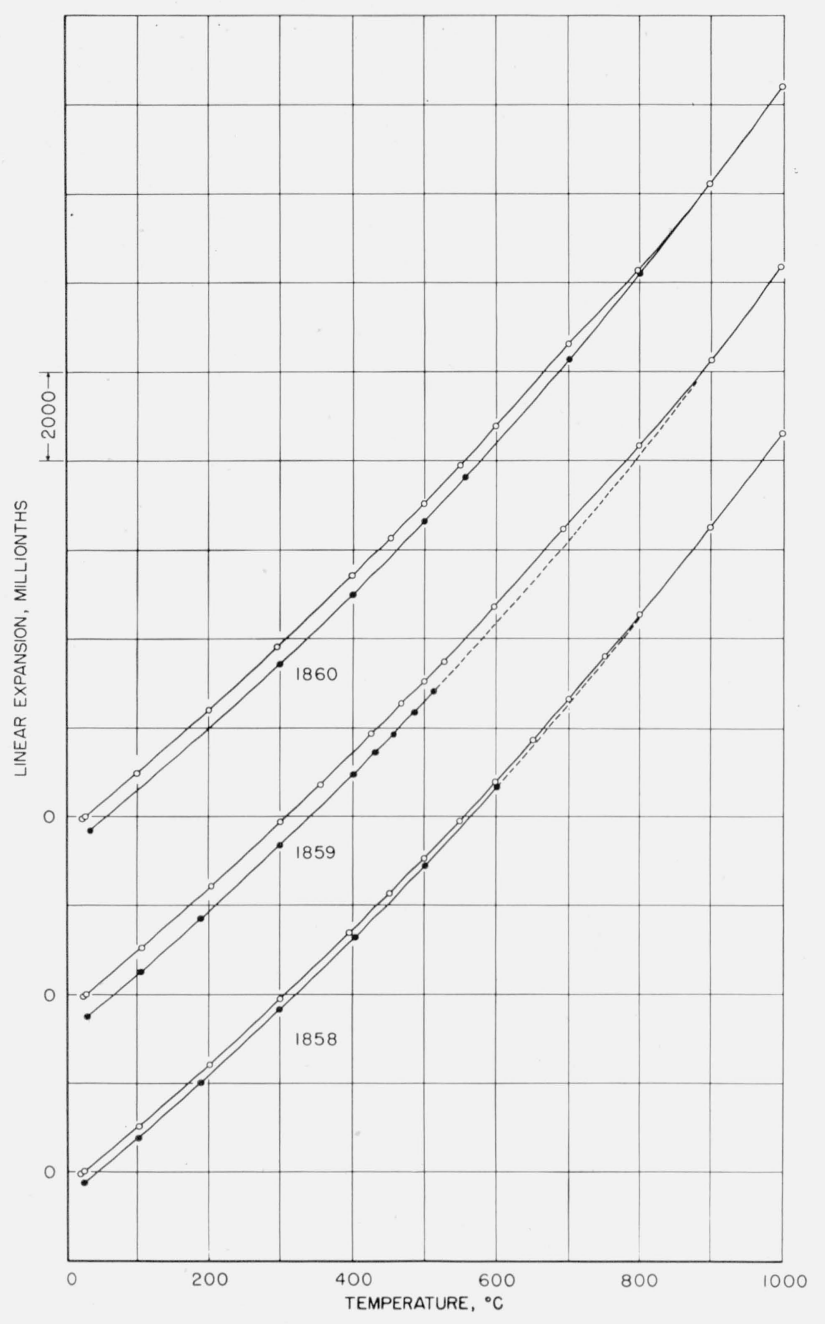

Figure 1. Linear thermal expansion of three Inconel alloys containing 0.02 to 0.11 percent of carbon.

$\bigcirc$, Heating; cooling.

Figure 4 shows the observations obtained on thermal expansion of Waspalloy at various temperatures from room temperature to $1,000^{\circ} \mathrm{C}$.

The coefficients of expansion of the nickel alloys containing 76 to 97 percent of nickel agree with the corresponding coefficients of nickel within $\pm 0.5 \times 10^{-6}$ per $\operatorname{deg} \mathrm{C}( \pm 3$ percent).

A comparison of the coefficients of expansion of the samples of Monel metal with those for nickel indicates that the addition of 27 to 29 percent of copper to nickel increases the coefficients of expansion by a maximum of $1.4 \times 10^{-6}$ per deg C (10 percent).

The coefficients of expansion of Illium alloy and Waspalloy containing appreciable contents of a variety of elements are appreciably less than those for nickel for various ranges between $20^{\circ}$ and $700^{\circ} \mathrm{C}$.

Figure 5 summarizes coefficients of expansion of nickel-chromium alloys with and without additions of other elements, for the range $20^{\circ}$ (or $0^{\circ} \mathrm{C}$ ) to $100^{\circ}$

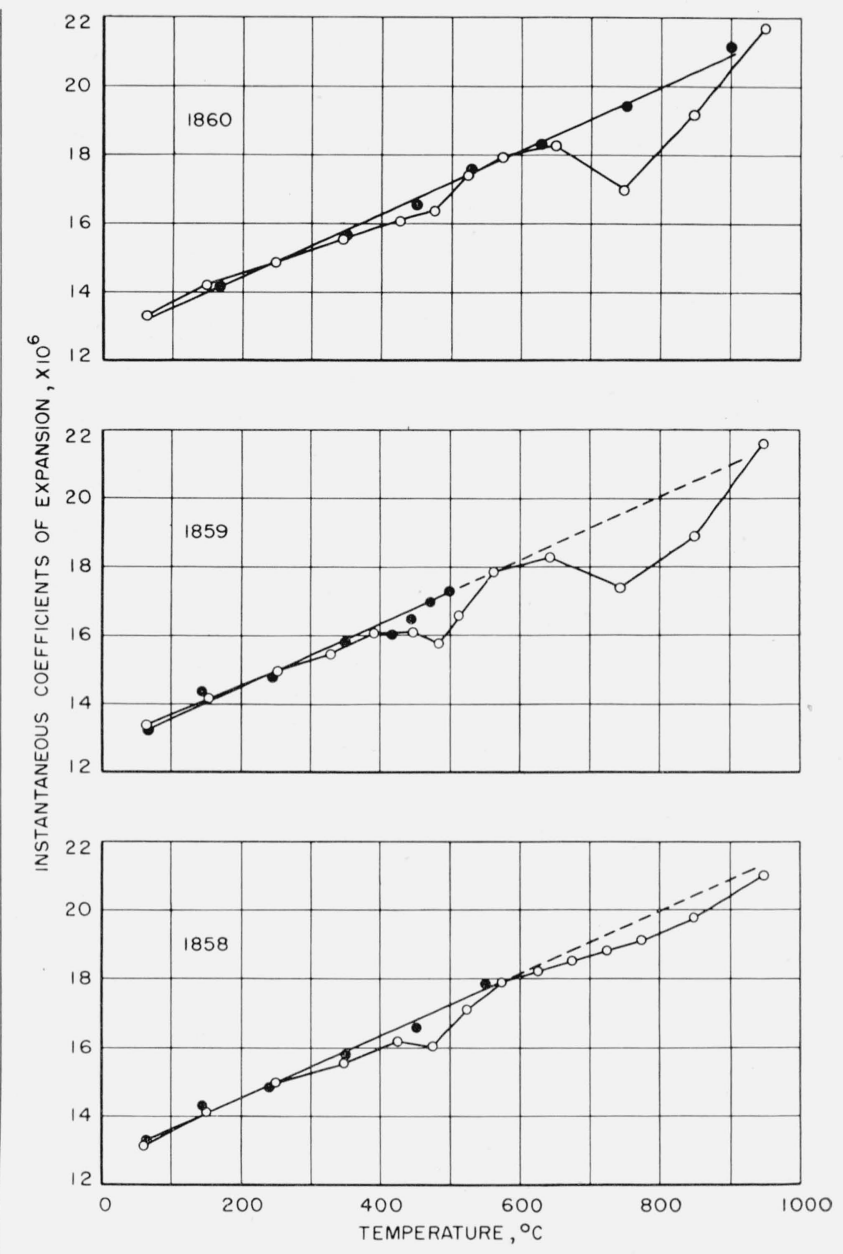

Figure 2. Instantaneous coefficients of linear expansion of Inconel alloys containing 0.02 to 0.11 percent of carbon.

○. Heating; • cooling.

$\mathrm{C}$, from the results in table 1 and other investigations $[3,4,5,6,7]$. The straight line represents the relation between the coefficients of expansion and the chromium content of the nickel-chromium alloys. This line indicates that the coefficient of expansion increases slightly with increase in the chromium content. The addition of 11 percent of cobalt or 7 percent of copper with other elements (10 percent) to nickel-chromium alloys reduced the coefficients of expansion appreciably. The effect of the addition of iron with or without other elements is indicated in the figure.

Data on the linear thermal expansion of other nickel alloys investigated at the Bureau were published in previous papers [3, 8].

The author expresses his gratitude to R. K. Kirby for his assistance in the determinations on thermal expansion of Inconel alloys, Monel metal (sample 1861), and Waspalloy. 


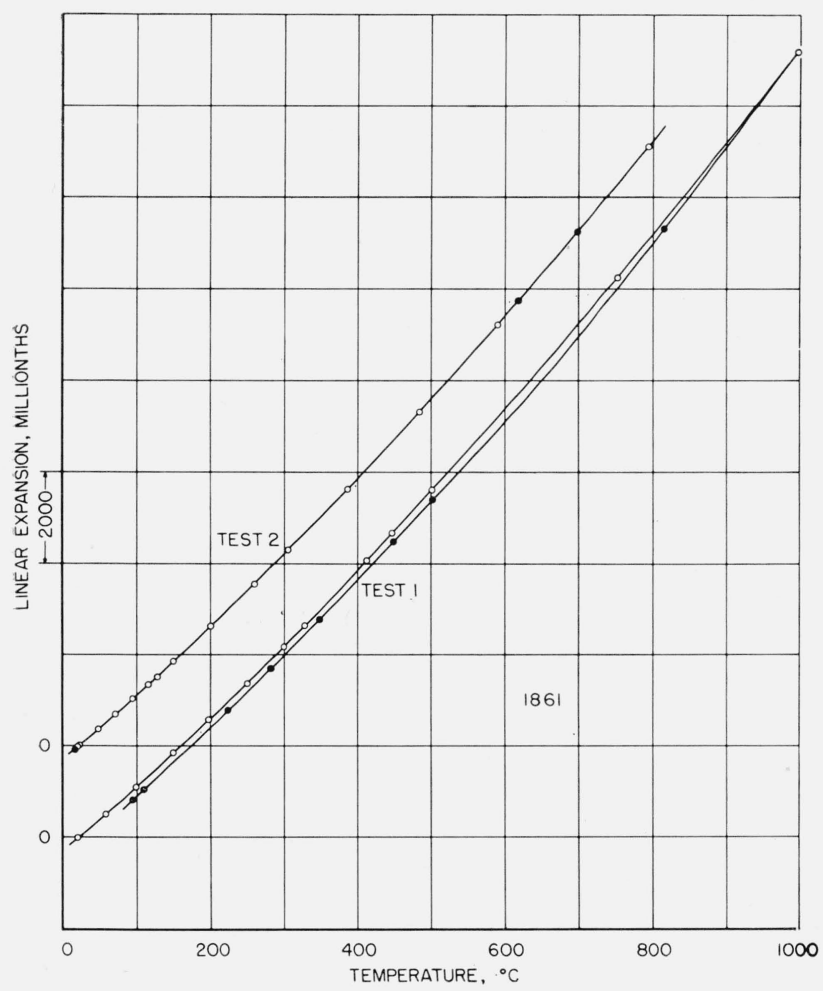

Figure 3. Linear thermal expansion of Monel metal (sample 1861).

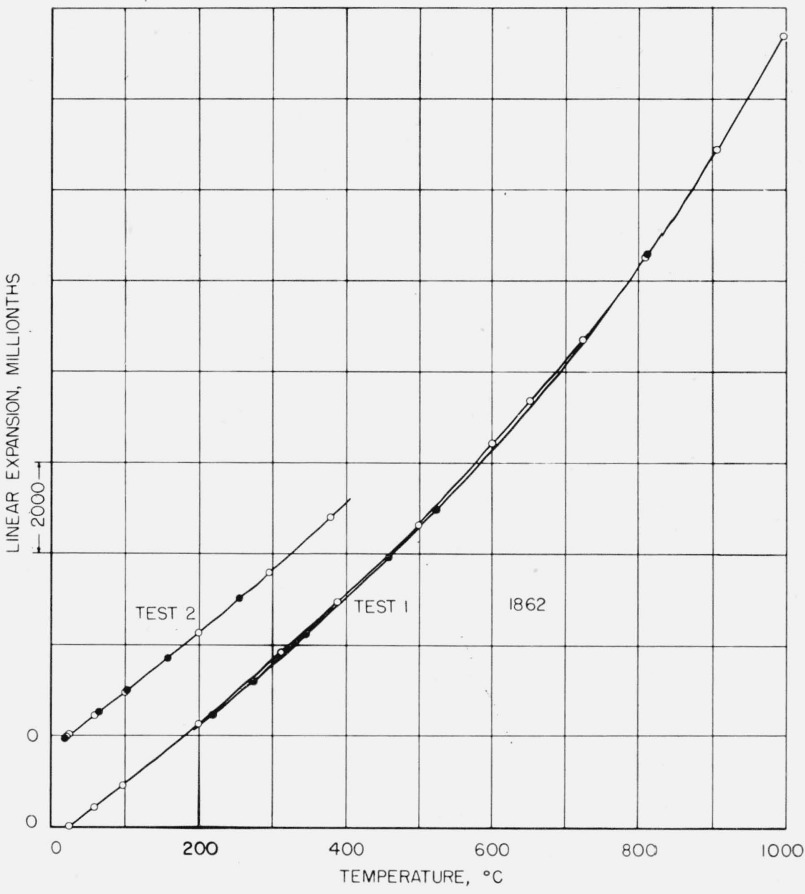

Figure 4. Linear thermal expansion of Waspalloy. $\mathrm{O}$, Heating; cooling. $\bigcirc$, Heating;

, cooling.

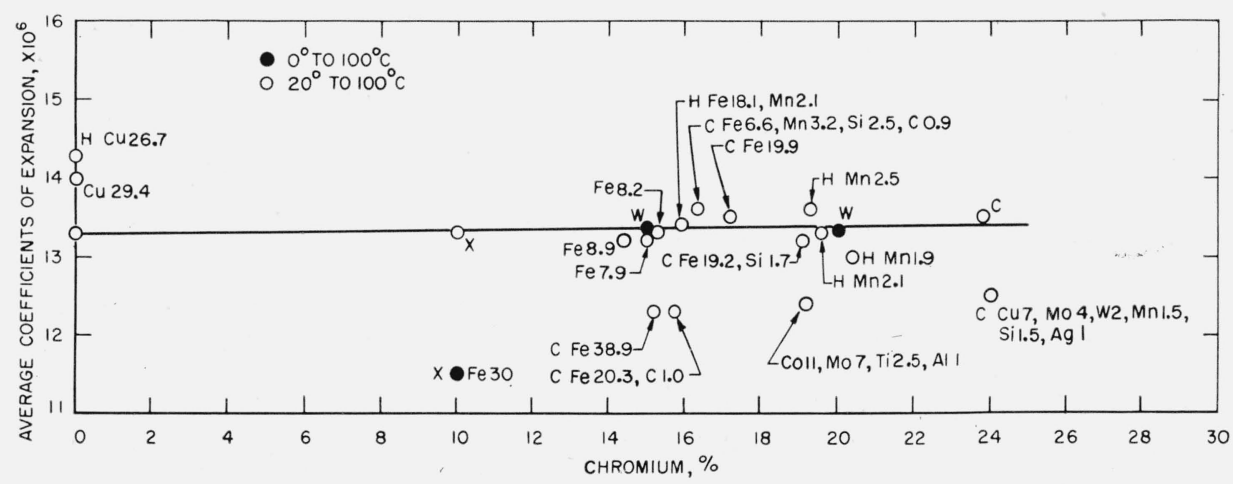

Figure 5. Coefficients of linear expansion of nickel-chromium alloys with and without additions of other elements.

All plotted points represent values for annealed alloys, except those marked with one of the following symbols: C, Cast: $\mathrm{H}$, hot rolled; $\mathrm{W}$, wrought; $X$, unknown treatment.

\section{References}

[1] P. Hidnert and W. Souder, Thermal expansion of solids, NBS Circular 486 (1950).

[2] W. J. O'Sullivan, Jr., Some thermal and mechanical properties of Inconel at high temperatures for use in aerodynamic heating research, Proc. Am. Soc. Testing Materials 55, 757 (1955).

[2a] Private communication from E. N. Skinner, International Nickel Co.

[3] P. Hidnert, Thermal expansion of heat-resisting alloys: nickel-chromium, iron-chromium and nickel-chromiumiron alloys, BS J. Research 7, 1031 (1931) RP388.

[4] P. Chevenard, Dilatomètre différentiel enregistreur, Rev. mét. 14, 610 (1917); Compt. rend. 164, 916 (1917).
[5] Symposium on corrosion-resistant, heat-resistant and electrical-resistance alloys, Proc. Am. Soc. Testing Materials 24 (2), 189 (1924).

[6] W. A. Dean, An investigation of some of the physical properties of the iron-nickel-chromium system, Rensselaer Polytechnic Institute, Engineering and Science Series, No. 26 (1930).

[7] P. Goerens, Die Eigenschaften der Edelstähle, Stahl u. Eisen 44 (2), 1645 (1924).

[8] W. H. Souder and P. Hidnert, Thermal expansion of nickel, Monel metal, stellite, stainless steel, and aluminum, Sci. Pap. BS 17, 497 (1922) S426.

Washington, September 19, 1956. 